\title{
CODE PHILOSOPHY
}

\author{
O.A. Glogau*
}

\section{SYNOPSIS}

This lecture presents background information on the philosophical framework within which some of the more important decisions were made and which led to the final proposal for the seismic provisions for New Zealand NZS 4203 "Code of Practice for General Structural Design and Design Loaciings". Aspects of ductility and seismic design coefficients for various types of structure are considered with illustrations to show how the new code covers the necessary design requirements. The design principles lying behind the code requirements are discussed, particularly for concrete frame and shear wall type structures. The interaction between earthquake motion of the subsoil and motion of the structure is also discussed. A number on unresolved problems are highlighted, particularly those concerned with short period structures. long acceleration seismic pulses, the damping-amplification relationship and mathematical modelling. Overseas codes are compared showing latest developments and illustrating the wide range of values used for the basic requirement. The lecture concludes with a consideration of likely future development and the manner in which the code is likely to be updated in the future.

\subsection{INTRODUCTION}

The objectives of the code are given in the model building by-law portion of the code and need not be repeated here. They differ little from those set by the codes of other advanced countries $(1,2,3)$ : and indeed from those given in the (little read) commentary on the present New Zealand Code (4).

Setting desirable general objectives is thus not particularly difficult for a code committee, but quantifying requirements that will achieve these objectives is not an easy task. The committee must produce a set of mandatory clauses and guidelines that will achieve a reasonable level of protection for life and property at an acceptable cost. They should take into account the relative seismicity of New Zealand as compared with other countries, its general standard of living, locally established building practices, available materials, and design methods.

The depth of detail with which a code should spell out its requirements is subject to considerable difference of opinion amongst engineers. Some wish to see no more than a statement of objectives, and undoubtedly, given a capable designer and a progressive client the result can be excellent. Unfortunately, in a real life situation the probability of both these two conditions occurring together is small and general requirements on their own, such as "buildings shall have ductility" are ineffective in competitive design, and even less so in "design and build" situations.

Accordingly, it has been the committee's majority view, based on past experience, that

* Chief Structural Engineer, Ministry of

Works and Development, New Zealand. the objectives of the code will be achieved only it it spells out its minimum criteria in considerable detail. It is also important that a code does not create conditions under which competent and conscientious designers are forced to choose between the limited interest of their clients and those of the general public at large. An example of this is the situation that nearly always arises if the requirements for protection against nonstructural damage are not made sufficiently specific.

Providing adequate restraints while avoiding overly restrictive clauses that will stifle sophisticated and innovative methods is one of the most difficult tasks for code committees. One of the features of the code that eased this task was the manner of presenting mandatory and commentary clauses on opposite pages in close association. This approach is particularly useful when dealing with a subject, such as earthquake engineering, in which developments are rapid but many "grey" areas remain. Guidance given in the comment should be helpful to the busy designer but allow some scope for alternatives to those willing to spend the time and effort to investigate in depth.

It has been recognised that engineers must make design decisions in situations where the facts are imperfectly known and the committee has not shunned its responsibility in avoiding vagueness wherever possible. The conventional decision-making process in areas where there is lack of sufficient information from earthquake damage and/or research includes that time honoured approach used by all committees review of overseas codes and drafts, intuition, and finally committee consensus following careful review of all comments. Invariably some requirements are fairly arbitrary but hopefully - notwithstanding the standard 
joke about a camel being a horse designed by a committee - these arbitrary requirements should be better and more representative than were they based on one man's opinion only. Camels after all are better than horses for the purpose they were designed for!:

Since it is outside the scope of this lecture to discuss detailed aspects of the code, this is done only where they highlight some of the more unusual and important features.

\subsection{DUCTILITY}

The 1965 New Zealand code included some vague references to ductility. How this was to be achieved was far from clear and the only available guidance was a slightly modified version of the SEAOC requirement contained in the New Zealand Concrete Code. Very few non public buildings of less than four storeys in height were detailed with the aim of achieving ductility, whereas the lessons from San Fernando (1971) and Tokachi-oki (1968) are clear - all buildings regardless of height must be designed to possess some degree of ductility. The code distinguishes between the degree of ductility that should be available in ductile structures designed to low $\mathrm{S}$ factors (.8 to 1.2) and that available for other structures. Ductile structures, which include both frames and shear walls, capable of dissipating seismic energy in a flexural mode at locations and in a manner specified by the code, should possess "adequate ductility". Some guidance is given in the code with regard to what is meant by "adequate" by specifying the number and magnitude of excursions into the inelastic range which a structure should be capable of without exceeding a given loss of strength during the process. In the case of conventional designs these requirements may be assumed to have been met by compliance with the detailing rules given in the material codes, their pending revisions or in suitable reference publications.

The term ductility without the qualification "adequate" is used to describe the much less well understood réquirement for systems that dissipate energy in a shear mode. These systems must be designed for loadings derived from $S=1.6$ or more. In severe earthquakes, damage is expected but, because of the geometry of these systems, total instability is unlikely to result. Research is being undertaken into the behaviour of these systems but progress is fraught with difficulties because the testing of even scaled down simplistic representations of real buildings requires large capacity equipment and expensive models.

\subsection{TOTAL HORIZONTAL SEISMIC FORCE}

The new code introduces the concept of a multi-term evaluation of the horizontal seismic design co-efficient to be applied to various structures. Just how many separate factors should be given was one of the more difficult decisions that the committee had to make. Obviously many more parameters affect the performance of a structure and if known with adequate precision the committee would probably have favoured their inclusion. More factors tend to give more choice to designers without any significant increase in design effort. After all, factors can readily be combined into simpler expressions. However, it was considered that at present adequate data was lacking and in fact several co-efficients given are no more than a broad reflection of the committee's combined view of expected earthquake performance and there is unavoidable overlap of several parameters. If for instance a presumed difference of $3 \%$ in damping between a structural steel frame and a reinforced concrete frame building represents a 1.3 factor in peak response, then the performance of the structural steel building designed using $M=0.8$ would need to be 1.7 times that of a reinforced concrete frame using $M=1.0$. Differences in undercapacity factors tend to increase the gap by a further 10\%. In practice the required difference in ductility is usually much less because stiffness criteria have to be met and in many instances are the critical design consideration. Nevertheless the comment made with regard to the requirements for reinforced concrete detailing also applies to structural steel.

The committee is well aware that ultimately all factors including those specified in the material codes are reflected in the design. It was not overlooked for instance that reinforced masonry would generally be designed for horizontal loadings that were $1.6 \times 1.2 / 0.8=2.4$ times the loading for ductile reinforced concrete frames and additionally that lower material undercapacity factors would apply. At the same time this large difference was based on, and made conditional to, significant improvements being made to current design and detailing of the reinforced concrete ductile shearwalls and frames $(6,13)$

It does not appear to be generally appreciated just how wide the range of the multi-term derived $c_{d}$ values is, particularly when several of the factors differ by no more than 10 or $20 \%$. In the following only the range of factors commonly in use have been included - extreme values of risk and unusual structure types have been excluded:

$\begin{array}{ll}\text { ZONING } & \begin{array}{c}\text { Short period range } \\ =0.15 / .1=1.5 \\ \text { Long period range } \\ =0.075 / 0.05=1.5\end{array} \\ \text { SOIL FACTOR } & \begin{array}{r}\text { Short period range }=1 \\ \text { Long period range } \\ =0.0825 / 0.05=1.65\end{array} \\ \text { IMPORTANCE } & 1.6 / 1=1.6 \\ \text { STRUCTURE } & (\text { Category } 1-6) 1.6 / 0.8=2 \\ \text { MATERIALS } & \begin{array}{l}1.2 / 0.8=1.5 \\ \text { RISK }\end{array} \\ & (\text { Categories } 1 \text { and } 2 \text { only) } \\ \text { DYNAMIC ANALYSIS } & 1 / 1 / 1=1.1=1.11\end{array}$

TOTAL RANGE (Short period) $=8.8$

Reference has already been made to the fact that many of the terms are uncertain in magnitude. In Japan the zoning range ( 3 zones) is only $1.0 / 0.8=1.25$ but in U.S.A. it is 4. Japan uses at present a combined soil and construction factor with a range of $1.5 / 0.6=2.5$. In California the range 
of structure factors is 2 (or 2.86 if shear and diagonal tension requirements are included).

Recently severe (provisional) requirements for hospitals have been introduced in California, see Figure 2, whereas SEAOC in their 1974 code specify an I factor of 1.5 for essential facilities.

The value of $\mathrm{C}_{d}$ in the equation $\mathrm{V}=$ $\mathrm{C}_{d} \mathrm{~W}_{t}$ where $\mathrm{C}_{\mathrm{d}}=\mathrm{CrSMR}$ is one of the important parameters in providing satisfactory earthquake resistance and some general comments on its level for various structures may be useful.

\subsection{Ductile Frames}

In suitably designed and detailed ductile frames the level of $C_{d}$ has an important effect on the area of the hysteresis loop available for energy dissipation. Low $C_{d}$ values result in large inelastic response and hence large ductility demand. Given the present state of the art of detailing reinforced concrete $(6)$ or structural steel the level of $\mathrm{c}_{\mathrm{d}}$ required by this code may be marginally too low.

For purposes of this discussion we may accept the validity of elastic response spectra as giving a broad indication of ductility demand. Let us consider further a severe but by no means maximum credible earthquake of the "Skinner" Spectrum type (scaled to $1 / 3 \mathrm{~g}$ maximum ground acceleration). If subjected to this earthquake, a class III, category 2 reinforced concrete building with 0.4 second fundamental period and possessing say $5 \%$ damping will be subject to an overall displacement ductility demand of $\frac{0.33 \times 2.33}{0.15}=5$. Local ductility demands are significantly greater than overall ductility demand so that most buildings are likely to suffer some structural damage in an earthquake of this size unless detailing is improved $(6)$. The majority of reinforced concrete buildings will be designed for $C_{d}$ values $20 \%$ lower (category 1) and where a dynamic analysis has been carried out the value could be even lower. Design to lower $\mathrm{c}_{\mathrm{d}}$ factors increases ductility demand but is compensated for by the fact that many buildings will be at least $20 \%$ stronger than indicated by $C_{d}$ values because the probable yield strength of the steel is greater than the minimum assumed and Bauschinger effects produce increased stress levels beyond that at first yield during subsequent loading cycles.

The 1965 New Zealand code envisaged that reduction factors of only 4 would be required as it was thought, and that was probably correct for the types of structures then built, that $10 \%$ damping could be expected during intense ground motions. There are a number of reasons why the basic level of seismic co-efficients for ductile frames has been somewhat reduced:

(1) Given the design and detailing principles of the code the performance of ductile frames should be better than that of those designed and detailed under the present provisions for a higher $C_{d}$ value, with much less attention given to, and knowleage of other aspects of the design.

(2) No direct evidence from earthquake damage is available with regard to the lack of effectiveness of the type of provisions contained within this code.

(3) Well proportioned structures may respond less intensely than is predicted from elastic response spectra derived for single mass systems.

(4) Improved structural detailing procedures are in advanced stages of development.

(5) Reduced requirements for the horizontal loadings of ductile frames would help to "pay" for urgently needed upgrading of other aspects of the 1965 New Zealand code provisions.

\subsection{Partially Ductile Shear Walls}

The 1965 New Zealand code considered that squat shear wall buildings would possess sufficient damping to compensate for the increased response due to other causes. Historically the performance of shear wall buildings has been very good at least from the point of view of protection of life and nonstructural components. This good performance was partially due to the bulk of these buildings being low structures with walls perforated by relatively small openings and possessing strengths greatly in excess of the minimum required by the codes.

Modern structures are more likely to have walls that are deep membered frames or isolated squat piers of no more than code level strength, and these structures cannot generally be expected to perform satisfactorily if designed using the low $C_{d}$ values specified for ductile frames. Systems dissipating most of the seismic energy in a shear mode are stiffness degrading systems which have much greater response than ductile flexural systems exhibiting relatively stable hysteretic behaviour. Detailing measures known at present can only delay the degradation process and therefore satisfactory performance requires design to a higher loading. Furthermore, the behaviour of many of the "shear failing" wall systems is difficult to predict and may vary from ductile flexural, to shear failure or rocking. The bulk of structures in this category are of short period which adds to the uncertainty of the behaviour $(9,10)$.

Direct evidence that the 1965 New Zealand code loading levels are insufficient for this type of structure comes from investigations into the failure or severe damage to many structures during the 1968 Tokachi-oki earthquake (11). These conventionally designed and detailed structures of less than 4 storeys were built to resist $0.2 \mathrm{~g}$ at working stresses and were of a construction standard at least equal to that in New Zealand. It is noteworthy that the earthquake had its epicentre at a distance of some $250 \mathrm{~km}$ and recorded ground accelerations were only $0.225 \mathrm{~g}$ maximum. Very extensive investigations carried out in Japan indicated that only those structures capable of resisting the equivalent of a horizontal static load of ig remained completely undamaged.

For partially ductile shear walls, the code specifies a level for $C_{d}$ of twice that for ductile buildings in category 1 , thus giving a resultant ultimate level of $c_{d}$ for a class 111, reinforced concrete structure 
of only $.24 \mathrm{~g}$ and for reinforced masonry $0.29 \mathrm{~g}$. These load levels are lower than those for which the Tokachi-oki structures were designed, but are probably the maximum acceptable at present. To minimise damage during earthquake attack, the code recommends detailing measures that will promote the formation of a distributed system of cracking of controlled width.

SEAOC (12) required higher loadings for "box systems" the equivalent of our category 4 structures. These systems not only have to be designed to twice the values for ductile frames but additionally the load factor for shear design has to be increased from 1.4 to 2.0 as well. Refer figure 1.

\subsection{Ductile Shear walls}

The value of $C_{d}$ specified for the various types of shear walls which qualify for inclusion into category 3 or 4 is roughly comparable to that for ductile frames. Reference (13) contains most of the background material that led to this decision.

\subsection{Other Structural Systems}

Apart from the diagonal bracing system capable of plastic deformation in tension only which has been the subject of limited research only (14), the code makes some provision in the small buildings section for a few structural types that do not properly fit one or the other categories. The performance of these types of structure is less predictable than that of others, but established practice, particularly in the presumed seismically less active northern regions of this country made it necessary that the code should make some provision for them. Whether or not the loading specified by the code and the built-in restraints are adequate is not clear at this stage, therefore the skill and integrity of the designers and the vigilance and competence of the vetting authority may play an (uncomfortably) large role in ensuring a satisfactory design.

\subsection{DESIGN PRINCIPLES}

This section is the most important addition to the original draft of the code which was circulated for comment. It had become clear that the information in the existing material codes or their proposed draft revisions was inadequate and that designers required some guidance. Because of its importance clause 2.3.1.1 of the section on Energy Dissipation and Capacity Design, will be repeated in its entirety here:

Design shall be in accordance with the relevant New Zealand Standard for the structural material concerned provided that the general principles of design set out below shall be followed:

(a) Buildings shall be designed to dissipate significant amounts of energy inelastically under earthquake attack.

(b) Buildings designed for flexural ductile yielding, or for yielding in diagonal braces, shall be the subject of capacity design. In the capacity design of earthquake-resistant structures, energydissipating elements or mechanisms are chosen and suitably designed and detailed, and all other structural elements are then provided with sufficient reserve strength capacity to ensure that the chosen energy-dissipating mechanisms are maintained throughout the deformations that may occur.

Columns or walls which are part of a two-way horizontal force resisting system shall be designed for the concurrent effect resulting from the simultaneous yielding of all beams framing into the column or wall from all directions.

The code then proceeds to give detailed recommendations for frames and walls aimed at achieving the above objectives.

The state of the art is such, however, that considerable caution is required if we are to be reasonably succesful. The response of a structure itself is uncertain and will be discussed later, but so is the distribution of loads within the structure. Studies using numerical integration response analysis techniques into the post-elastic range have indicated that even in regular buildings with conservatively designed columns current methods of analysis and design cannot exclude the possibility that column hinges will form, possibly at both ends within a single storey. The distribution of beam capacity moments into columns is also very uncertain as the number of storeys that will simultaneously form beam hinges and hence the appropriate column axial loads is no more than an educated guess. Provided stringent detailing measures are taken, formation of a column hinge for a short period of time is probably not disasterous even in a RC column but any condition that could result in non-ductile failure is serious, and therefore to avoid this type of failure conservative assumptions are necessary. Assumed axial loads have an important bearing on flexural capacities and these in turn on column shears. The least researched parameter is the vertical earthquake effect. Measured amplification of the vertical components of ground motions have been very high at San Fernando, but just how damaging these are when occurring over a short interval of time in combination with horizontal motion effects is not known at present. Theoretically the ductility aemand on upper storey columns and beams is significantly increased. Some arbitrary, modest provision was made in the original draft of this code but designers, already struggling to prevent columns from lifting due to the axial tension induced by several storeys of hingeing beams, found the provisions very difficult to meet in practice. Until more factual information becomes available the committee decided to relegate vertical earthquake effects, excepting those on horizontal cantilevers, to a non-specific commentary clause.

Column hinge mechanisms as distinct from other column hinges are not permitted except in structures of less than two storeys and in top storeys. This requirement is intended to avoid the extremely high ductility demands that result from side sway mechanisms. Recent research into the behaviour of buildings with soft first storeys (15) revealed the extreme complexity of the whole subject of inelastic response. 
Perhaps the most interesting result of this study was not the very large (expected) first storey drifts but the unreliability of the soft first storey as a "safety fuse" for the protection of upper storeys. Even when the yield strength of the first storey was reduced to $1 / 10$ th of that of a normal structure it transmitted shear forces greatly in excess of its yield value, thus resulting in large ductility demand in the storeys above. (The elastic stiffness was not varied). Only when the first storey provided essentially an elastic-perfectly plastic mechanism and in addition had a greatly reduced yield strength, were the transmitted forces limited. The particular study also highlighted the need to consider earthquake requirements on a statistical basis as the authors who had used twenty different motions in their study concluded:

"Analysis of response due to 1 or to even several earthquakes is likely to be quite misleading".

The subject of concurrency has been adequately discussed in reference (18).

The uncertainties of seismic load distribution are compounded by the uncertainties in the behaviour of joints and members $(6,16)$. The detailing of cantilever shear wall structures is far from resolved. One of the most significant parameters, the magnitude of the shear forces corresponding to the yield capacity moment is not well established, but a recent study (17) indicates that they have been greatly underestimated in the past. How damaging these relatively short high shear stress peaks are is not known at present.

A number of modifications were made to the original draft to cope with the design of squat shear walls. If the requirements of capacity design for ductile walls were applied to these systems several anomalies would arise. It seemed unreasonable to require the shear strength of these walls, which are presumed to fail in shear to exceed that of their flexural yield capacity. In the case of walls possessing relatively low shear strength as for example reinforced masonry walls, the minimum reinforcement introduced for other purposes such as face loadings, shrinkage etc. is sufficient to give these walls yield capacities that exceed any reliable shear strength they can be expected to possess. In fact wall geometry usually precludes ductile behaviour. In section 3.1 .2 reference has been made to the rather more severe SEAOC requirements (see also fig. 1). Flexural reinforcement required in squat walls for purposes of resisting in-plane stresses is as a rule no problem. One reason for not lowering the $S$ factor to that used for flexure for structures of categories 1 to 5 is that the behaviour of many category 6 structures is rather unpredictable. Even if some sort of flexural behaviour were exhibited by a structure in this class, or some of its members, this would not automatically constitute "adequate ductility".

Foundation design for squat shear walls was another difficulty that led to modifications to the original draft. Rocking of shear walls, although little investigated to date, appeared to be an acceptable alternative to dissipating seismic energy by shear, provided it did not take place at too low levels of response. Accordingly rocking of shear category 6 walls is permitted at loadings corresponding to approximately $S=1.3$ and for any system at a level of $S M=2$. More research is urgently needed particularly with regard to the likely movements that will take place during rocking to enable the designer to evaluate the consequences.

\subsection{SUBSOIL EFFECTS}

Qualitative consideration of subsoil effects on the response of structures has been recommended since 1965 (4), hence more definite requirements contained in the new code. Some of the reasons as to why this was done only in very broad terms, are given in reference (7) and these include: lack of uniqueness of site period and damping characteristics which are dependent on amplitude of shaking. Of particular interest in this regard is a comprehensive set of recordings made to determine the response of the earth fill SANNOKIA Dam (Okamoto et al, 1966). The ratio of maximum crest acceleration to maximum base acceleration varied from about 5 for base motions of $0.03 \mathrm{~g}$ to about 2 for motions of $\mathrm{lg}$.

Interesting too are simultaneous recordings taken in Japan on and below the ground surface $(10)$. In an earthquake with accelerations approx. $0.1 \mathrm{~g}$ at ground surface near the Earthquake Research Institute, Tokyo, only half the value of accelerations were measured at basement level. Similarly accelerations measured on the ground in another location in Tokyo were 3 to 6 times greater than those $15 \mathrm{~m}$ underground in an earthquake with peak accelerations of about $0.01 \mathrm{~g}$. From response spectra of the motions it has been determined that the large surface amplifications predominantly applied to short period waves but not to those with longer periods for which the ratio tended towards 1. Umemura (10) suggests that as much as a $50 \%$ reduction in design co-efficient for short period buildings with basements could be appropriate $(0.2 \mathrm{~g})$ and supports this by lack of damage to rigid buildings with basements in Japan.

Some designers may have hoped the code would contain recommendations for code curves relating building period to site period as has been done in the 1974 SEAOC provisions. Perhaps a reference to fig. I comparing SEAOC flexible soil and AlJ stiff soil curves is in order to put the matter in perspective.

The following example discussed in reference (5) will highlight the difficulties. Figures $4 \mathrm{~A}$ and $4 \mathrm{~B}$ are relative velocity spectra of ground motion records taken during the San Fernando earthquake of February 1971. Figure 4A shows relative velocity spectra less than $\frac{1}{2} \mathrm{~km}$ apart (fig. 3 ) on similar depths of alluvium. Figure $4 \mathrm{~B}$ shows that the maximum responses on rock (SI site) were the same as those on $900 \mathrm{ft}$ of alluvium (ATH site).

Hudson (5) reviewing records from 20 ground stations during the San Fernando 
earthquake concluded that it appeared that local surface and subsurface topography might overshadow the influence of local site conditions and that another earthquake might be equally complicated but quite different at any particular site. Some evidence of a similar nature has also been observed in N.Z. $(22)$. Earthquake motions, particularly those of distant earthquakes are significantly modified by subsoils. The effect of surface layers has been compared to that of a frequency filter and power amplifier. As a result some ground motions may be amplified to a much greater degree than others. It is thought that the serious damage to low modern reinforced concrete structures at Tokachi-oki ( 8 ) 1968 could be attributed in part to the spectrum modifying characteristics of the surface layer.

\subsection{SOME UNRESOLVED PROBLEMS}

Almost every aspect of aseismic design and analysis contains elements of uncertainty some of which will be discussed in other papers at this seminar. A number of aspects are of particular importance to a loading code. For instance, one of the questions that could not be answered with any degree of certainty was whether the basic design co-efficients of the code result in a reasonably consistent degree of protection for structures of varying fundamental period but of otherwise similar type and material. Regions of particular uncertainty appear to be the level of the basic co-efficient for structures of less than 0.4 sec period and that for those greater than say $2 \mathrm{sec}$.

Even if one accepts that earthquake response spectra for buildings on stiff soils are reaonsably well modelled by the shape of the "Skinner" spectrum envelope, a scaled down version of this shape may not be a satisfactory guide for the design of structures on which overall displacement ductility demands of 4 or more may be made. At first sight it might appear that the flat portion of the code curve for periods less than $0.45 \mathrm{sec}$ is over-conservative since damped elastic acceleration response spectra on stiff soil have a falling branch in this region. Surprisingly the question concerns the exact opposite - namely whether for buildings of less than 0.4 sec designed to code levels excessively high ductility demand could result ( 9 ). There is considerable uncertainty about the low frequency content of earthquake ground motions and it would be very imprudent to design longer period structures to a sfaled down EI Centro curve. SEAOC (12) recognising this have over the course of years lifted and flattened their curve in this region and their 1974 curve for average conditions where site resonance is not specifically investigated is now well above all N.Z. curves between $3 / 4-2 \sec$ (fig. 1 ).

A source of particular concern in the design of structures relying on significant inelastic behaviour for their survival is our lack of knowledge of the number and characteristics of large and long acceleration pulses. The effect of these pulses is comparable to applying a horizontal static force exceeding the capacity of a structure, rendering even the best hysteretic behaviour ineffective. Some of the damage at the olive View Hospital complex during the 1971 earthquake has been attributed to an early long pulse only half as intense as the later peak $(23)$. If a long pulse occurs at a stage during an earthquake when a structure's elastic resistance has already been exhausted, then obviously the intensity of a long pulse leading to failure need not be very great.

If the prescence of such long pulses is a reasonably high probability in earthquake motions considerable caution would need to be exercised with regard to relating code design curves to linear elastic response spectra.

Designers wishing to investigate the behaviour of their structures using a numerical integration response analysis will need to use the results within the limitations imposed by other analysis methods specified by the code. This method is a valuable research tool but the validity of the result depends on the character of the ground motion used, the chosen damping factor and the mathematical model of the structure. Because the committee was unable to make recommendations for several of these vital parameters limitations had to be imposed to avoid large differences in strengths and stiffness resulting from varying assumptions. Difficulties with regard to specifying an appropriate suite of earthquake motions has already been discussed above and under subsoil effects but even if the ground motion were of a less random nature the problem of response would be far from resolved.

The table below compares recommended damping values by two authoritative organisations. The difficulties associated with determining suitable damping values are due to the fact that the values depend not only on the structure but also its nonstructural components and further on the

RECOMMENDED DAMPING RATIOS

\begin{tabular}{|l|c|c|c|}
\hline & $\begin{array}{c}\text { B.R.I. } \\
\text { Japan }\end{array}$ & $\begin{array}{l}\text { Los Angeles } \\
\text { City Draft }\end{array}$ & \multicolumn{1}{|c|}{ Comments } \\
\hline Steel frame & 0.01 & $0.02-0.05$ & $\begin{array}{l}\text { L.A. values vary with } \\
\text { fabrication and cladd- } \\
\text { ing. }\end{array}$ \\
\hline $\begin{array}{l}\text { Reinforced } \\
\text { concrete frame }\end{array}$ & 0.03 & $0.05-0.10$ & $\begin{array}{l}\text { L.A. depending on } \\
\text { structure type cladding } \\
\text { etc. }\end{array}$ \\
\hline
\end{tabular}


intensity of motion. Few if any records have been obtained from buildings dissipating energy inelastically during an earthquake.

Damping has a significant effect on amplification as is shown in Fig. 5 where values given by several authors are compared. The range of values for a given o of damping during elastic response is almost 100\%. Obviously the error introduced by uncertainties in damping varies with the fundamental period of the structure and the spectral intensity of the motion. Equivalent viscous damping is most effective for motions resembling harmonic motions and at peak response. Much less error results for low regions of response i.e. a 60 storey structure subjected to an E1 Centro 1940 NS motion, and for inelastic responses during which a large amount of hysteretic damping is present.

Another important parameter, the mathematical model of the building is also very imprecisely known, particularly the force restoring characteristics of the system (shape of hysteresis loops) which generally varies with each cycle. Even the most ambitious computer programs use radically simplified models of real 3-dimensional structures, particularly for RC. Little is known for instance of the extent to which floor slabs and secondary beams participate at high levels of concurrent inelastic response.

The code as a matter of practical necessity does not require foundations to be designed for forces greater than those resulting from $\mathrm{SM}=2$. For zone $A$ class 111 structures no foundation needs to be designed to a level greater than $0.15 \times 2$ $=0.3 \mathrm{~g}$. The implications of this provision particularly with regard to rocking are not well understood.

\subsection{COMPARISON WITH RECENT OVERSEAS CODES}

Figures 1 and 2 are composites relating the seismic loading provisions of NZS 4203 to that of some Californian and Japanese codes. An adequate comparison requires normalising of curves to allow for differences in load factors and whether the earthquake load is derived from dead load only (as is generally SEAOC practice) or includes a portion of the live load. Significant also is whether the negative beam moments are determined from a combination of load factored dead and live loads and earthquake and if so what load factors are used. Californian and N.Z. practice differ considerably in this respect because N.Z. provisions include some live loads in the derivation of the earthquake load but unity load factor for dead load is used in the load combination of gravity and earthquake. For purposes of this comparison the two opposing effects of these varying approaches between the N.Z. and Californian requirements have been considered as self cancelling.

The Japanese provisions shown are those widely applied to high rise construction which is subject to approval by a high rise building committee. They are much more severe than NZS 4203 but the seismicity of Japan is 10 times that of N.Z., at least in the terminology used by seismologists. Figure 6 shows that many Japanese buildings have been constructed to these high loadings including 50 and 60 storey buildings. Of particular interest is the fact that the minimum values is $0.05 \mathrm{~g}$ and is not reached until the fundamental period becomes $3 \frac{1}{2}$ to over 7 seconds. Until recently designs were carried out using seismic steel stresses of only $1 \frac{1}{2}$ times those allowed for gravity loadings, but currently the allowable seismic stresses for structural steel are close to yield level.

The current Japanese code for ordinary structures places a penalty of $1 \% \mathrm{~g}$ for every 4 metres in height over 16 metres. Subject to adjustments by a soil and construction factor of from 0.6 to 1.5 and normalised for allowable stresses the minimum design co-efficient in the highest Japanese seismic zone would be about $0.25 \mathrm{~g}$ at ultimate load.

Composites of code curves such as those shown in Fig. 1 must have a sobering effect on any thoughts one might harbour that earthquake engineering is an exact, even reasonably exact science. It is likely that international agreement on disarmaments would be easier to reach than agreement on a code design curve. If it were merely a matter of scale this could readily be explained by differences in regional seismicity but other features such as the wide plateau of $0.2 \mathrm{~g}$ in the Japanese curves for buildings up to 0.9 sec even for stiff soils may have other reasons. Tradition? Maybe.

\subsection{LIKELY FUTURE DEVELOPMENTS}

The wealth of unresolved problems and the flood of new information naturally raise questions as to the future of the code. The writer advocates a gradual development of the code rather than the present practice of a traumatic 10 yearly complete overhaul. The new format of the code, which minimises problems of adoption by local bodies is well suited to such an approach. The principle of more frequent and therefore more gradual updating is in line with overseas trends e.g. ACl. obviously changes would and should not be made unless there is solid evidence preferably from earthquake damage that a requirement in the code is inadequate, otherwise inconvenience to designers and clients will result.

The committee has endeavoured to convince SANZ that updating of the code should be on a regular yearly basis such as is done for instance with the "Uniform Building Code". Although unable to obtain SANZ assurance that this could be done until there is a significant improvement in technical and support staff levels of that organisation, the committee will press ahead with efforts of its own to complete review of the code in the light of designers experience by mid 1976. The present edition should be available from SANz early 1976.

In many instances updating may take the form of alternative approaches to supplement existing requirements. There is for instance no provision for reliability design procedures. There are good prospects that the next code will contain recommendations for the design of members subject principally to gravity loadings at least on a semiprobabilistic basis. Seismic considerations 
however increase the complexities enormously and progress is uncertain. Even in highly seismic areas with records available for a long period rational prediction of sequence of earthquake shakings that a building will experience during its lifetime is at present extremely uncertain. Presuming that adequate data on seismicity of a region is available we must still estimate attenuation of intensity over the distance between the hypocentre and the site.

Figure 7 shows the derivation of an expression relating ground acceleration with focal distance. Note that the scatter is over 100 times in the region of greatest interest. The strongly elongated pattern of isoseismal lines in figure 8 are evidence of the same complexity in the relationship between distance and earthquake effects. For rock motions other authors (20) are less pessimistic.

Lack of statistical data as well as reliable data is of course no ground for entirely rejecting a probabilistic basis for design. The minimum information required for the evaluation of safety and for design is the expected value (e.g. the average) of each design variable plus a measure of uncertainty (e.g. its co-efficient of variation). Indeed it is true of probabilistic models that the significance of data based objective information, or lack thereof, can be reflected properly in combinations with necessary engineering judgement.

Experience has however shown that where the measure of uncertainty in data is high, probabilistic approaches lead to more stringent requirements than the safety requirements obtained by traditional approaches which are apparently acceptable to society.

\subsection{CONCLUSION}

The writer believes that this code is an advanced and practical standard which provides a reasonable level of protection to life and property at an economic level in cost taking into account the relative seismicity of N.Z. as compared with other countries, and the total cost of a building's construction.

\subsection{REFERENCES}

(1) Rosenblueth, E. and Esteva, L.: Poyecto de Reglamento de las Construcciones en el Distrito Federal: Folleto Complementario: Vol. 2, Mexico 1962 .

(2) Design Essentials in Earthquake Resistant Buildings, Architecture Inst. of Japan.

(3) Basic Design Criteria of the Recommended Lateral Force Requirements and Commentary ASCE. ST9, Sept. 1972.

(4) MP12, Commentary on Ch. 8, NZSS 1900, $1965, \mathrm{Cl} .5 .3, \mathrm{Cl} .10$.

(5) Hudson, D. E.: Local Distribution of Strong Earthquake Ground Motions. Bull. S. Soc. of America, Vol. 62, No. $6,12 / 72$.

(6) Blakeley, Megget and Priestley: Seismic Behaviour of Two Full Size RC Beam/ Column Joint Units, Bull. of the N.Z.N. S.E.E., March, 1975.

(7) Taylor, P. W.: Earthquake Design Formula Considering Local Soil Consid- eration. Discussion ASCE ST6 June 1972, pp. 1336-1338.

(8) Yamahara, H.: The Interrelation Between Frequency Characteristics of Ground and Earthquake Damage to Structures. Japan Society of Soil Mech. Vol. X, No. I, 1970.

(9) Skinner, R. I. and McVerry, G. H.: Base Isolation for Increased Earthquake Resistance of Buildings. South Pacific Regional Conference on E.E., Wellington 1975.

(10) Umemura, H.: Earthquake-Resistant Design of Structures, University of Tokyo, p.47.

(II) General Report on the Tokachi-oki Earthquake in 1968.

(12) Recommended Lateral Force Requirements and Commentary. Structural Engineers Association of California 1974.

(13) Paulay, T.: Report on Design Aspects of Shear Walls for Seismic Areas, University of Canterbury, 1974, p.29.

(14) Bazan and Rosenblueth: Technical Note, Journal of the ASCE, Feb. 1974 , ST2, pp. 489-493.

(15) Chopra, A. K.; Clough, R. W. and Clough, D. P.: Earthquake Resistance of Buildings with a Soft First Storey. Earthquake and Structural Dynamics, Vol. 1, 1973.

(16) Park, R. and Paulay, T.: Ductile RC Frames. Bulletin of the N.Z.N.S.E.E., Vol. 8, No. 1, March, 1975.

(17) Blakeley, R. W. G.: Cooney, R. C. and Megget, L. M.: Seismic Shear Loading at Flexural Capacity in Cantilever Wall Structures. South Pacific Regional Conference on E.E. "Wellington 1975.

(18) Armstrong, I. C.: Capacity Design of Reinforced Concrete Frames for Ductile Earthquake Performance, Bull. of the N.Z.N.S.E.E., Vol. 5, No. 4, 1972.

(19) Glogau, O. A.: The Objective of the N.Z. Seismic Design Code, Bull. of the N.Z.N.S.E.E., Vol. 5, No. 4, 1972 .

(20) Whitman, Biggs, Brennan, Cornell, de Neufville, Vanmarcke: Seismic Design Decision Analysis, MIT Structures Publication No. 385, 1974.

(21) Schnabel and Seed: Accelerations in Rock for Earthquakes in the Western United States (to be published).

(22) Stephenson, W. R.: Earthquake Induced Resonant Motion of Alluvium, Bull. N.Z.N.S.E.E., Vol. 7, No. 3, 1974.

(23) Bertero, Et al: "Design Implications of Damage Observed in the Olive View Medical Centre", Proceedings 5WCEE, Rome 1973, Vol. I.

(24) NZS $4203 \mathrm{~N} . \mathrm{Z}$. Standard Code of Practice for General Structural Design and Design Loadings. 


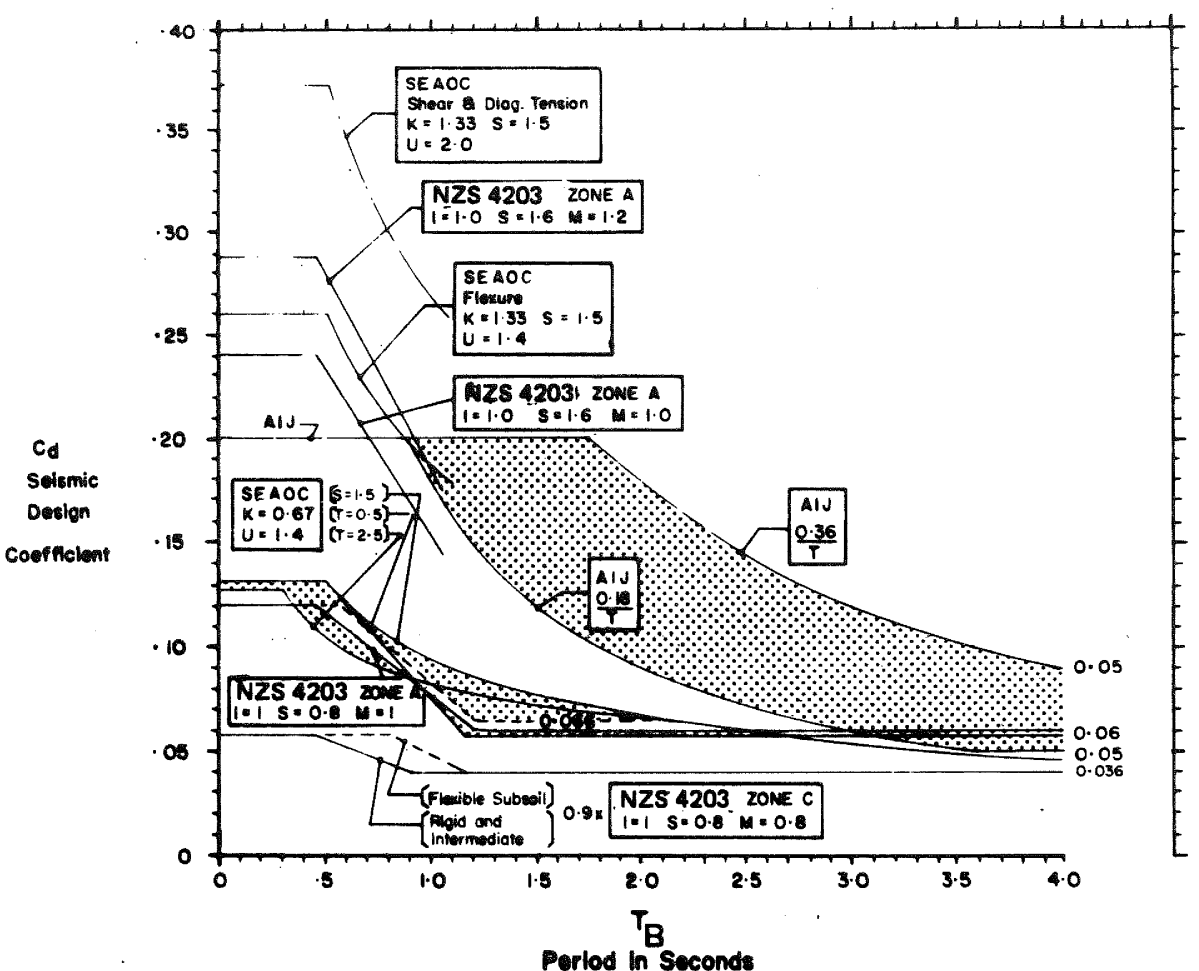

N.Z., S.E.A.O.C. and AlJ Soismic Deaign Coefficients

FIGURE 1

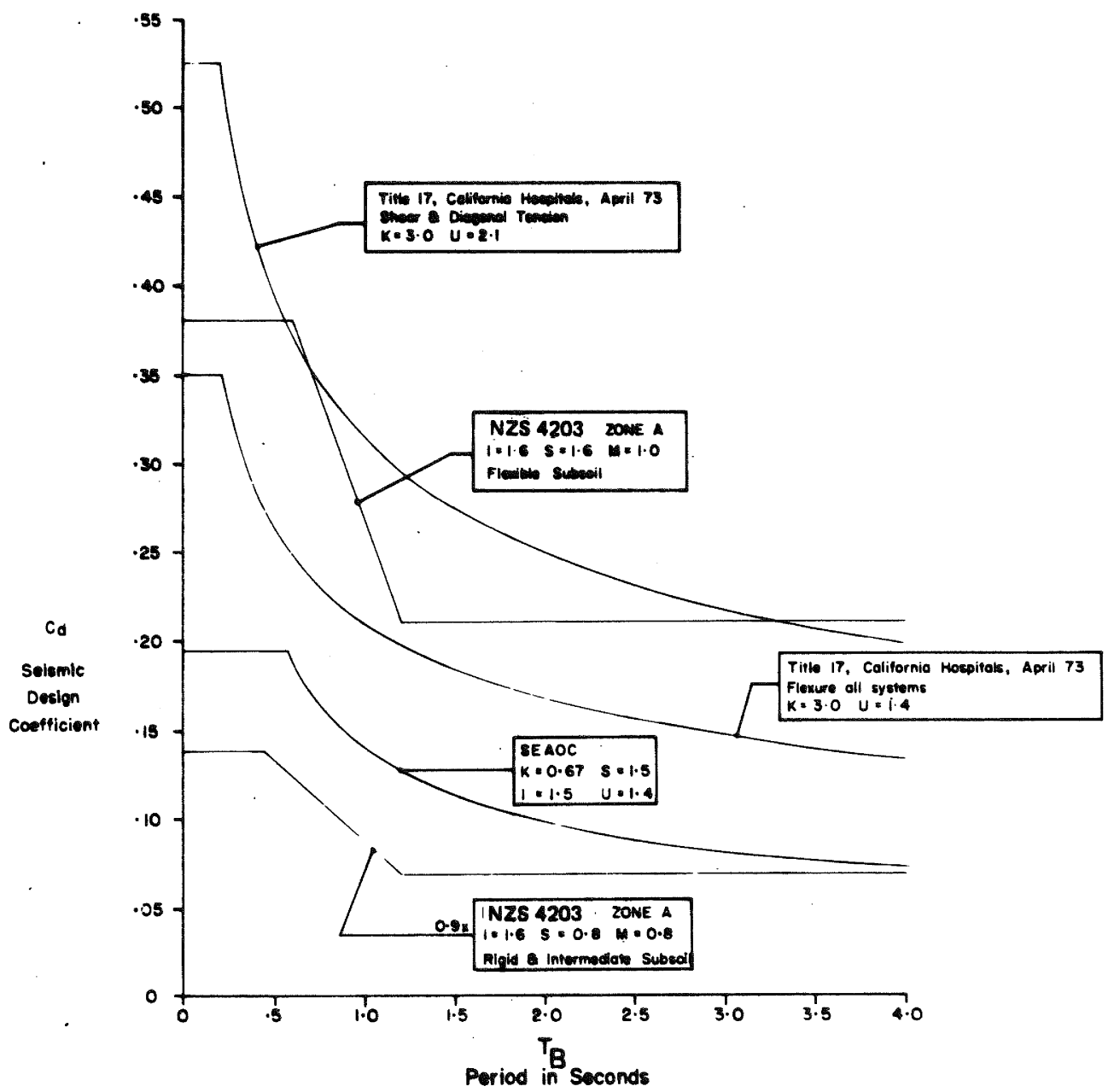

N.Z. S.E.A.O.C. Eesential Facilitibe and Titte 17 (Callfomb Hoeplitals) Seismic Design Coefficlents

FIGURE 2 


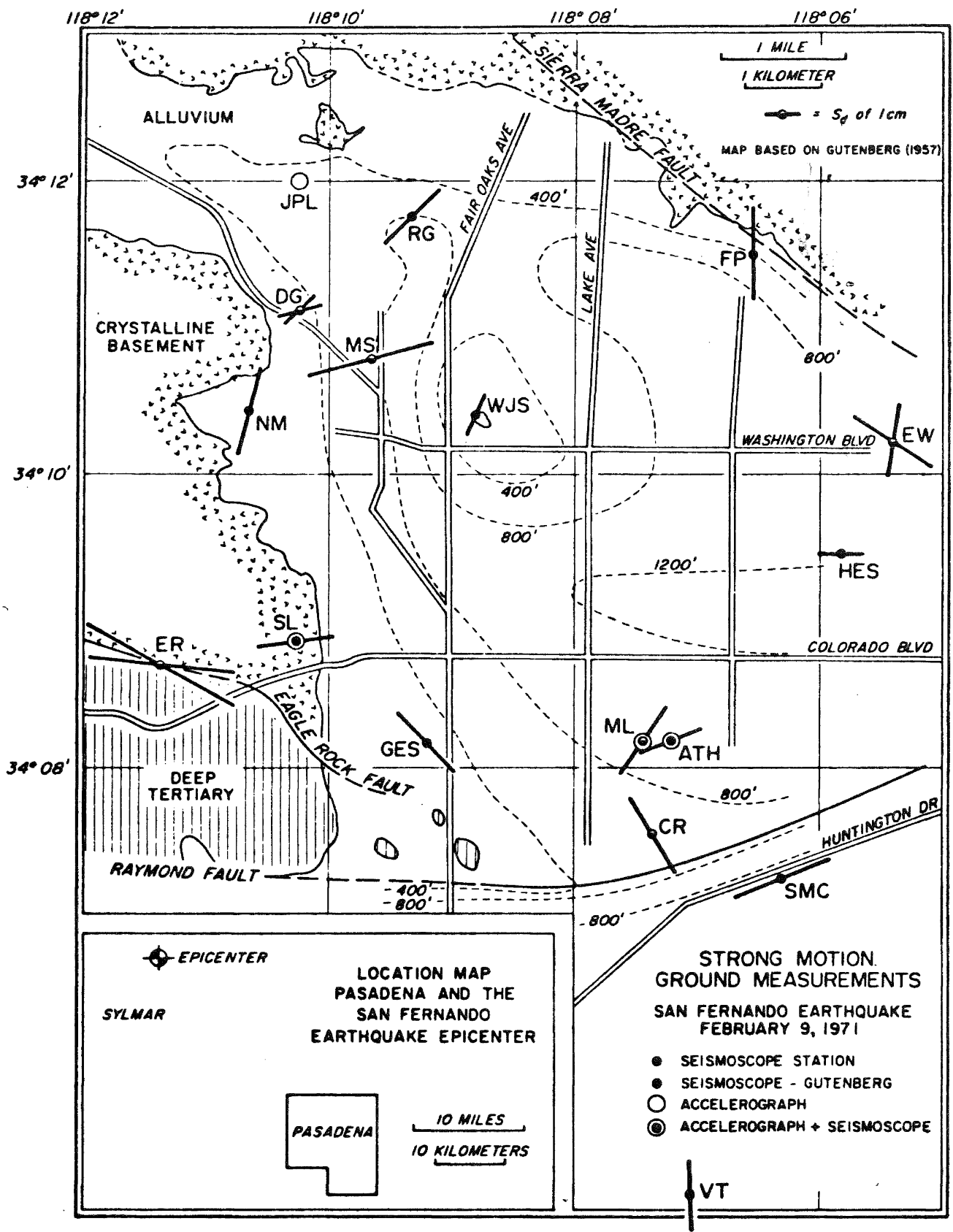

FIGURE 3 : LOCATION MAP AND MAXIMUM RELATIVE VELOCITY RESPONSE VALUES. 

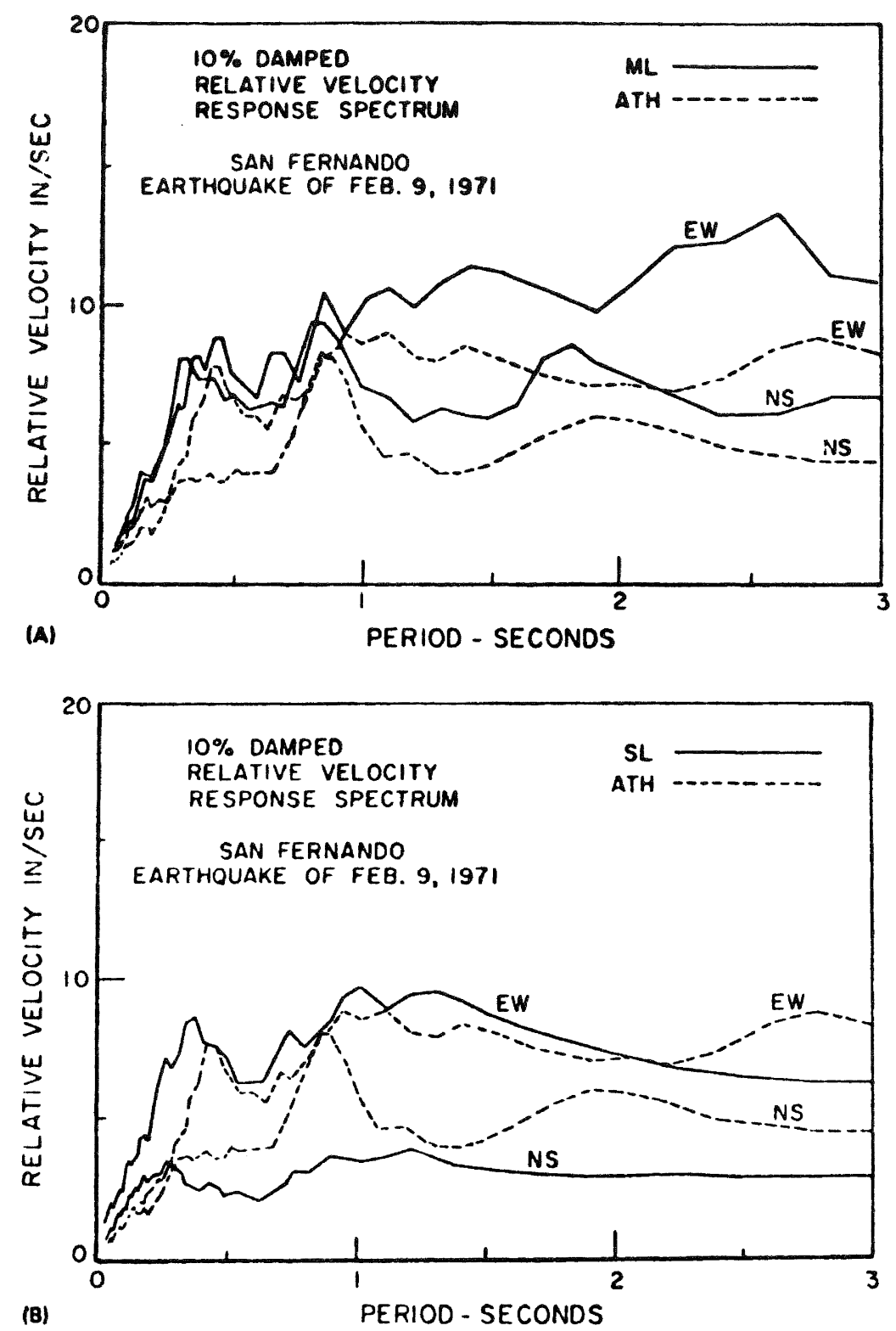

FIGURE 4 :COMPARISON OF VELOCITY SPECTRA

(A) MILLIKAN LIBRARY AND ATHENAEUM

(B) SEISMOLOGICAL LABORATORY AND ATHENAEUM

(C) SEISMOLOGICAL LABORATORY AND MILLIKAN LIBRARY, AND

(D) JET PROPULSION LABORATORY AND SEISMOLOGICAL LABORATORY. 

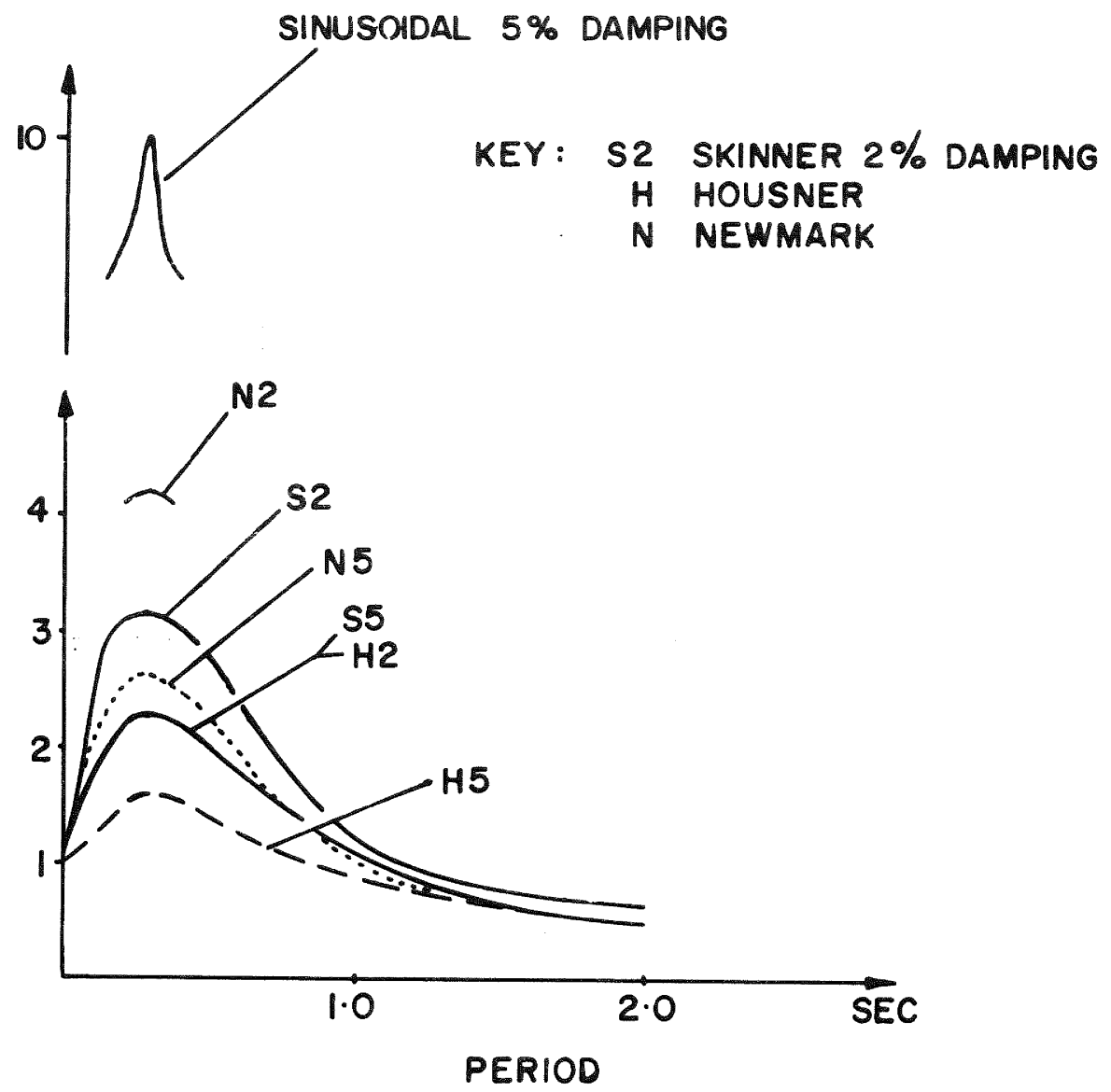

FIGURE 5 : COMPARISON OF AMPLIFICATION OF GROUND ACCELLERATION ACCORDING TO 3 AUTHORS

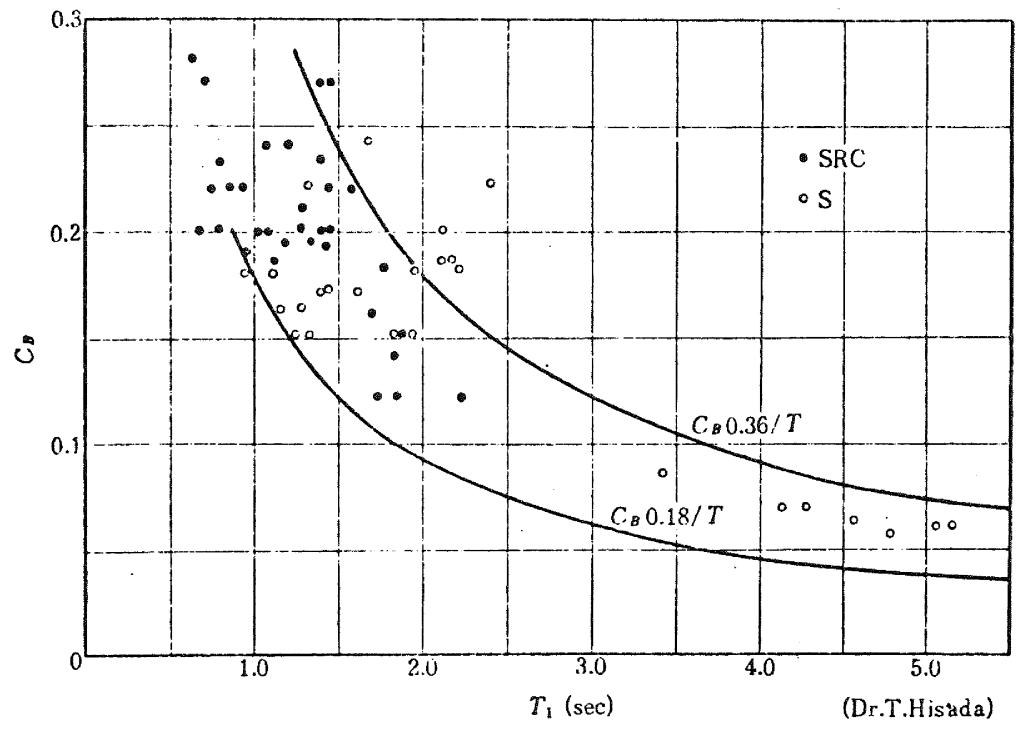

FIGURE 6 : RELATION BETWEEN DESIGN BASE SHEAR COEFFICIENT AND FUNDAMENTAL NATURAL PERIOD OF HIGH-RISE BUILDINGS 


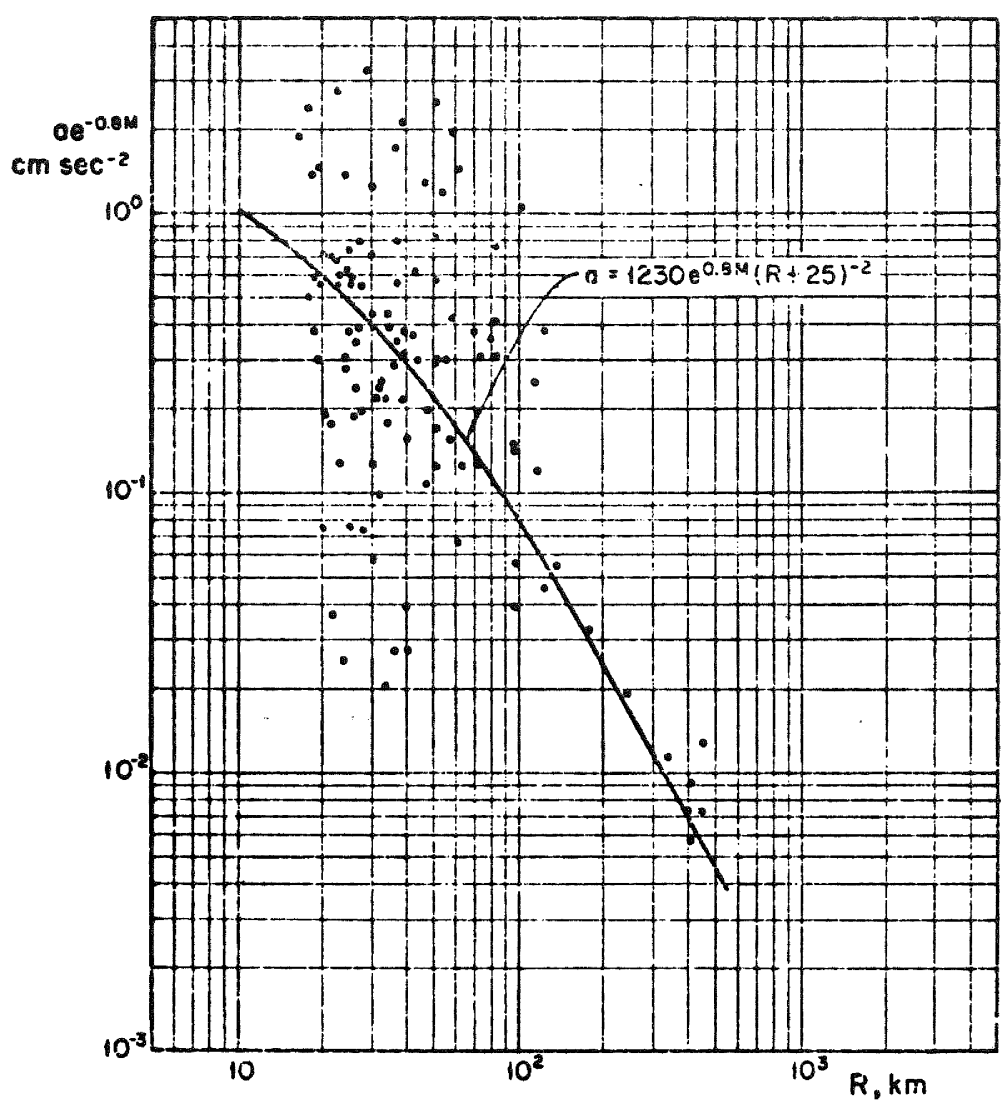

FIGURE 7 : VARIATION OF MAXIMUM GROUND ACCELERATION WITH FOCAL DISTANCE. AFTER ESTEVA (1969).

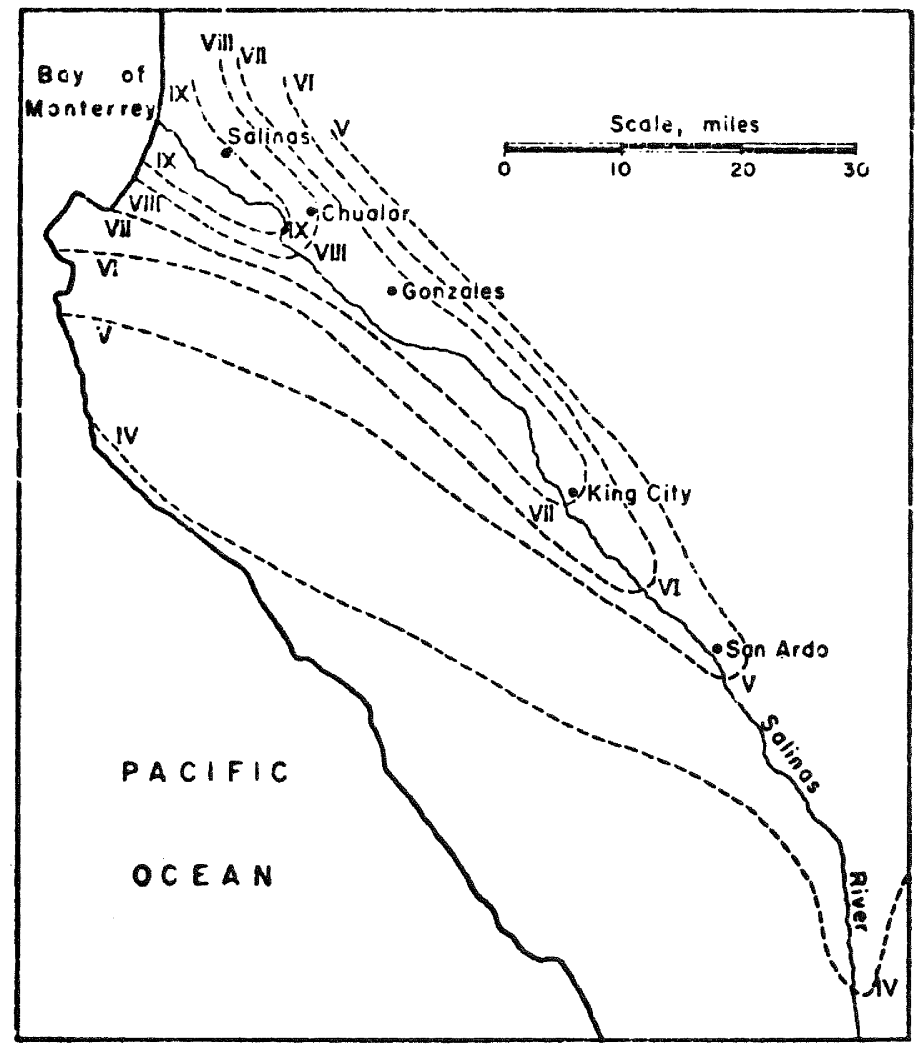

FIGURE 8 : ISOSEISMAL LINES IN THE SALINAS VALLEY, CALIFORNIA EARTHQUAKE, 1906. AFTER LAWSON (1908 AND 1910), REPRODUCED BY DAVISON (1936). 